\title{
Strengthening a societal tie and other new initiatives for 2019
}

\author{
Michael Stowasser, Editor-in-Chief ${ }^{1} \cdot$ Sunil k Nadar, Editor ${ }^{2} \cdot$ James Brian Byrd, Editor $^{3}$
}

Received: 23 January 2019 / Accepted: 23 January 2019

(c) Springer Nature Limited 2019

Having enjoyed a long affiliation with the British and Irish Hypertension Society (BIHS) and its predecessor, the British Hypertension Society, it gives us great pleasure to announce that the Journal of Human Hypertension will be formally recognized as the official journal of the BIHS from March of this year. This arrangement will serve to strengthen the relationship between these two entities and to impart major rewards to readers and members alike. In addition to JHH continuing to publish abstracts from the BIHS Annual Scientific Meeting, it will provide priority space for publication of statements and commentaries generated by the Society. Online access to JHH will now be available to BIHS members free of charge, and print access at a markedly reduced rate. In return, JHH will enjoy heightened visibility through the BIHS website, newsletters and social media, in addition to being a flagship journal for the publication of clinical hypertension research carried out by BIHS members.

We are also excited to introduce several new initiatives during 2019 that promise to enhance the quality, reach, and ultimately the impact of the journal on the world, as well as provide greater rewards to readers and authors. These initiatives, include (1) placing a greater emphasis on review articles contributed by Early Career Researchers in addition to more established authors, as well as focussing on "hot topics" such as pregnancy-induced hypertension, genetics, and device-based treatments. From time to time, JHH will publish debates on the more topical and controversial of these issues; (2) taking a pro-active role in publishing guidelines and position papers from hypertension societies and other authoritative bodies worldwide; (3) continuing to deliver special issues and web focusses; and (4) promoting the new JHH Young Investigator Award to recognize the achievements of our future leaders in human hypertension research.

Competition is fierce, but JHH is up to the task. With submission rates reaching an all-time high and only set to increase further with the strengthening of its affiliation with the BIHS under the expert leadership of Dr. Francesco Cappuccio, the future is looking very bright indeed for JHH, its readers, and human hypertension research in general.

We look forward to your ongoing readership throughout the year and beyond.

\footnotetext{
Michael Stowasser

m.stowasser@uq.edu.au

1 Princess Alexandra Hospital, Woolloongabba, Australia

2 Sultan Qaboos University Hospital, Muscat, Oman

3 Division of Cardiovascular Medicine, Department of Internal Medicine, University of Michigan, Ann Arbor, MI, USA
} 